\title{
Caracterização de frutos e sementes em acessos de maracujá silvestre (Passiflora foetida L.)
}

SOARES W.S. ${ }^{* 12}$; RÊGO M.M. ${ }^{13}$; RÊGO E.R. ${ }^{1{ }^{13}}$; BARROSO P.A. ${ }^{1,4}$; MEDEIROS L.R.N. ${ }^{1{ }^{15}}$. ${ }^{1}$ Laboratório de Biotecnologia Vegetal - Centro de Ciências Agrárias - Universidade Federal da Paraíba, 58397000, Areia-PB; e-mail: e-mail:wellington23santos@hotmail.com, mailson@cca.ufpb.br, elizanilda@cca.ufpb.br, pa.barroso@hotmail.com, leunmedeiros@zootecnista.com.br, ${ }^{2}$ Graduando em biologia, bolsista iniciação cientifica; ${ }^{3}$ Bolsista de produtividade em pesquisa-CNPq; ${ }^{4}$ Mestranda em agronomia, bolsista CAPES; ${ }^{5}$ Graduando em zootecnia, bolsista iniciação cientifica.

RESUMO: A espécie Passiflora foetida L.é uma trepadeira exótica cujas folhas e frutos possuem propriedades medicinais. No Brasil, a erva é utilizada na forma de extratos ou emplastros para erisipelas e doenças de pele com inflamação. O objetivo deste trabalho foi caracterizar cinco acessos de Passiflora foetida $L$. baseados em 17 descritores morfológicos $O$ experimento foi conduzido em casa de vegetação em delineamento inteiramente ao acaso, com 15 repetições por genótipo. As variáveis analisadas foram cor da casca do fruto, formato do fruto, comprimento do fruto, diâmetro do fruto, massa fresca do fruto, comprimento do pedicelo, cor da polpa do fruto, espessura da casca, acidez titulável, sólidos solúveis, potencial hidrogeniônico, razão sólidos solúveis/ acidez titulável, comprimento da semente, diâmetro da semente, espessura da semente, massa fresca das sementes e o número de sementes por fruto. Os dados foram submetidos à análise de variância e teste de médias pelo teste Tukey a $5 \%$ de probabilidade. Houve diferença significativa pelo teste $\mathrm{F}$ a $5 \%$ de probabilidade, entre os genótipos para quase todas as características com exceção da espessura da casca, massa fresca do fruto, comprimento da semente e massa fresca das sementes. A característica que apresentou maior variação foi o teor de sólidos solúveis. E entre os genótipos, o acesso 5 foi o que apresentou as maiores médias pelo teste de Tukey a $5 \%$ de probabilidade, em todas as características analisadas, podendo ser utilizado em programas de melhoramento da espécie.

Palavras-chaves: Planta medicinal, Frutos, Banco de germoplasma.

ABSTRACT: Characterization of fruits and seeds of wild passion fruit (Passiflora foetida L.). The species Passiflora foetida L. é an exotic vine, which leaves and fruit have medicinal properties. In Brazil, the herbis used in the form of extracts or poultices for erysipelas and skin diseases with inflammation. The aim of this study was to characterize five Passiflora foetida $L$. accessions based on 17 morphological descriptors The experiment was conducted in a greenhouse in a completely randomized design with 15 replicates per genotype. The variables were the fruit skin color, fruit shape, fruit length, fruit diameter, fresh fruit, length of pedicel, flesh color of the fruit, skin thickness, acidity, soluble solids, hydrogen potential ratio soluble solids / acidity, seed length, seed diameter, thickness of seed, fresh seed and seed number per fruit. The data were submitted to analysis of variance and the means were compared by Tukey test at $5 \%$ of probability. There was a significant difference by $\mathrm{F}$ test at $5 \%$, of probability among the genotypes for nearly all traits, except the thickness of the shell, fresh fruit mass, seed length and fresh weight of seed. The variable that most variation was the soluble solids. The genotype 5 had the highest means by Tukey test at $5 \%$ of probability on all characteristics that can be used in breeding programs of the species.

Key words: Fruit, medicinal plants, Germplasm bank. 


\section{INTRODUÇÃO}

O gênero Passiflora é originário da América do Sul e tem no Centro-Norte do Brasil, o maior centro de distribuição geográfica (Lopes, 1991). Entre as 530 espécies descritas para o gênero, mais de 150 são nativas do Brasil (Hoehne, 1946). Somente algumas têm importância econômica em função da qualidade dos frutos para consumo ou ainda por apresentarem propriedades medicinais. Vanderplank (2000) identificou as espécies de maracujazeiro como pertencentes à ordem Violales, tribo Passiflorae, família Passifloraceae, com 18 gêneros e cerca de 630 espécies, distribuídas essencialmente em regiões tropicais, sendo $95 \%$ delas predominantes na América do Sul e o restante na Ásia, Austrália e América do Norte.

O gênero Passiflora compreende trepadeiras herbáceas ou arbustivas, raramente eretas. Possui hastes cilíndricas ou quadrangulares, muito ramificadas, angulosas, suberificadas, glabras, que, em algumas espécies, podem apresentar-se pilosas e atingir 5 a $10 \mathrm{~m}$ de comprimento, composto de 22 subgêneros divididos em secções e/ou séries (Killip, 1938). A flor é muito característica do gênero, diferindo dos demais pela presença de cinco estames, cinco pétalas e cinco sépalas e pelo androginóforo ereto com estames de extremidades livres e três estigmas (Cervi, 1997).

$\mathrm{Na}$ maioria das espécies, as flores de Passiflora apresentam heterostilia, autoincompatibilidade e proterandria, que favorecem a polinização cruzada (Rego et al., 1999). Conforme a revisão do gênero Passiflora para o Brasil, atualizando e compilando a nomenclatura de diversas espécies, Cervi (1997) relata que as espécies silvestres brasileiras são encontradas, principalmente, em matas úmidas e, freqüentemente, crescem nas clareiras e nas bordas das matas. Possuindo grande valor ornamental e medicinal atribuído à variedade na exuberância das flores e frutos com suas formas em cores singulares dentro do gênero (Souza, 2003). A utilização das Passifloras como elementos decorativos, pode ser também uma medida de conservação desses germoplasma, uma vez que há entre as espécies ornamentais grande dissimilaridade (Bernacci, et al., 2005).

O conhecimento sobre plantas medicinais simboliza muitas vezes o único recurso terapêutico de muitas comunidades e grupos étnicos, o que explica o fato de ainda hoje, nas regiões mais pobres do país e até mesmo nas grandes cidades brasileiras, encontrarmos plantas medicinais sendo comercializadas em feiras livres, mercados populares e encontradas em quintais residenciais (Maciel et al., 2002).

Em nosso país, $20 \%$ de nossa população consomem $63 \%$ dos medicamentos disponíveis no mercado; o restante, ou seja, $80 \%$ da população de nosso país encontram nos produtos naturais, especialmente nas plantas medicinais, sua única fonte de terapia (Di stasi et al., 1996).

A seleção de plantas com possível poder farmacológico depende de diversos fatores que incluem: conteúdo químico, toxicidade e uso tradicional pela população em diferentes culturas, que é conhecido como etnobotânica, ou mais especificamente como etnofarmacologia (Rates, 2001). Esta constitui um desdobramento da etnobotânica e estuda os remédios simples ou compostos, produzidos a partir de vegetais. (Camargo, 2003).

As pesquisas com plantas medicinais envolvem investigações da medicina tradicional e popular (etnobotânica); isolamento, purificação e caracterização de princípios ativos (química orgânica: fitoquímica); investigação farmacológica de extratos e dos constituintes químicos isolados (farmacologia); transformações químicas de princípios ativos (química orgânica sintética); estudo da relação estrutura/ atividade e dos mecanismos de ação dos princípios ativos (química medicinal e farmacologia) e, finalmente, a operação de formulações para a produção de fitoterápicos (Maciel et al., 2002). Pesquisas realizadas já identificaram mais de 350 mil espécies vegetais, o que permite uma ampla variedade aos possíveis usos medicinais, entre estas estão às espécies que compõe o gênero Passiflora, que apesar do amplo uso popular, são ainda pouco estudadas do ponto de vista científico.

Na Nigéria, a infusão das folhas de Passiflora foetida L. é um exemplo claro na utilização no tratamento de histeria e insônia (Nwosu, 1999). Essa espécie é muito cultivada também na Índia, onde suas folhas são aplicadas na cabeça para o alívio de tonturas e dores de cabeça. No Brasil, a espécie é utilizada na forma de loções contra erisipela e outras doenças de pele (Chopra et al., 1956; Dhawan et al., 2001).

A Passiflora foetida $L$. apresenta grande variabilidade genética, porém em alguns países do mundo ela é considerada erva - daninha (Swarbrick, 1981). Seu florescimento se dá durante todo ano, onde a abertura das flores inicia-se pela manhã e seu fechamento se dá antes do meio dia, juntamente com as brácteas e estipulas possuem forte odor bem desagradável (Wagner et al., 1990). As sementes são achatadas, pretas em uma polpa doce e aromática (Swarbrick, 1981).

Como já foi descrito este maracujazeiro silvestre ( $P$. foetida L.) apresenta grande importância medicinal e a etnobotânica sugere a utilização não somente das folhas, mas também de seus frutos no tratamento da asma, icterícia, bem como na forma 
de emplastros para as erisipelas e doenças de pele com inflamação (Chopra et al., 1944), além de tratamentos em doenças como a Biliousnes (doença relacionada à má digestão, dores de estômago, constipação e flatulência excessiva), tonturas, etc (Deginani, 2001). Dentre os principais fitoconstituintes desta planta, encontram-se alcalóides, fenóis, flavonóides e compostos glicosídicos cianogênicos (Dhawan et al., 2004).

Porém, para conhecer e diferenciar espécies, variedades e acessos de maracujá e outras culturas são empregados descritores como os agronômicos, moleculares e botânicos. Acaracterização morfológica compõe o repertório dos descritores botânicos, compreendendo os parâmetros referentes à coloração, proporção e formato da planta e suas partes. Os parâmetros morfológicos são exigidos para o registro e proteção de cultivares e são definidos pelo Serviço Nacional de Proteção de Cultivares (SNPC) do Ministério da Agricultura, Pecuária e Abastecimento. A descrição botânica é extremamente importante para estabelecimento de um programa de melhoramento de Passiflora.

De acordo com Martinelli et al.(2001), o manejo eficiente de germoplasma vegetal é de vital importância para o pesquisador, que necessita do mesmo bem caracterizado para utilizá-lo em suas pesquisas e posterior melhoramento genético. Os estudos morfológicos em Passiflora foetida L. baseiam-se na caracterização física e química da planta, tendo um aspecto em particular como o fruto e suas respectivas sementes devido suas propriedades medicinais. Porém, há escassez de informações sobre a evolução e seus aspectos morfológicos (Ulmer \& Macdougal, 2004).

Deste modo o presente trabalho teve como objetivo caracterizar cinco acessos da espécie medicinal Passiflora foetida L., por meio de descritores baseados em características morfológicas, possibilitando assim uma maior riqueza de informações, sobre a mesma.

\section{MATERIAL E MÉTODO}

O material vegetal utilizado foi proveniente do banco de germoplasma de hortaliças do Centro de Ciências Agrárias da Universidade Federal da Paraíba (CCA/ UFPB), localizado no município de Areia no Estado da Paraíba (latitude de 6058'12 Sul e longitude de 3542'15" Oeste de Greenwich e altitude de 534 metros).

O experimento foi conduzido em campo experimental do Laboratório de Biotecnologia do CCA-UFPB, no período de março a dezembro de 2011. A semeadura foi realizada em bandejas de isopor (poliestireno) preenchidas com substrato comercial Plantmax ${ }^{\circledR}$ e quando apresentaram pelo menos 6 folhas definitivas foram transplantadas para vaso de $900 \mathrm{ml}$ contendo o mesmo substrato. Cinco acessos de $P$. foetida $L$. foram utilizados para o experimento comparativo. O experimento foi montado em delineamento inteiramente ao acaso. De cada tratamento foram avaliados 15 frutos maduros colhidos em julho de 2011. Sendo analisadas as seguintes características físicas para o fruto: cor da casca do fruto (CCF), formato do fruto (FF), comprimento do fruto (CF), diâmetro do fruto (DF), a massa fresca do fruto $(\mathbf{M g})$, comprimento do pedicelo (CP), cor da polpa do fruto (CPF), espessura da casca (EC), acidez titulável (AT), sólidos solúveis totais (SST), o potencial hidrogeniônico (pH), e a razão (SST/AT). No caso da análise das sementes foram observadas as seguintes características: comprimento da semente (CS), diâmetro da semente (DS), espessura da semente (ES), massa fresca das sementes (Mg) e o número de sementes por fruto (NS), totalizando assim 17 descritores avaliados.

As avaliações de diâmetro e comprimento do fruto e semente e a espessura da casca foram realizadas com o auxilio de um paquímetro. Em seguida, procederam-se as análises químicas: a AT e SST, segundo metodologia preconizada por Pregnolatto \& Pregnolatto (1985). Os dados foram submetidos à análise de variância com posterior separação das medias pelo teste de Tukey a $5 \%$ de probabilidade, para os dados quantitativos, utilizando o programa estatístico Genes (2001)

\section{RESULTADO E DISCUSSÃO}

Os coeficientes de variação (CV\%) do experimento variaram de $4,49 \%(\mathrm{pH})$ a $42,84 \%$ (MS), sendo satisfatórios, uma vez que foram detectadas diferenças significativas entre os acessos para a maioria das características analisadas.

Não houve diferenças significativas entre as médias dos genótipos em nível de $5 \%$ de probabilidade, pelo teste $F$, para as características espessura da casca, massa do fruto, comprimento da semente e massa das sementes (Tabela 1). Resultados divergentes em relação ao nosso trabalho foi relatado por Araujo et al. (2008), os quais encontraram diferenças significativas para massa do fruto e da semente, utilizando o mesmo procedimento e trabalhando com Passiflora cincinnata Mart. Houve diferença entre as médias para o $\mathrm{pH}$, que variou de 3,60 a 5,08, superior aquela relatada por (JUNQUEIRA et al., 2010), trabalhando com Passiflora nítida Kunth. $(\mathrm{pH}=3,61)$.

Com base na comparação de médias das características físico-químicas de frutos dos 5 genótipos de P. foetida L. (tabela 2) observou-se que para a característica $\mathrm{pH}$, a maior média foi do genótipo $5(\mathrm{pH}=5.08)$ e a menor para os genótipos 1 e $2(\mathrm{pH}$

Rev. Bras. Pl. Med., Botucatu, v.13, especial, p.569-573, 2011. 
TABELA 1. Resumo da analise de variância para cinco características da planta e nove de fruto em $P$. foetida $L$.. UFPB, Areia- PB, 2010.

\begin{tabular}{|c|c|c|c|c|c|c|c|c|c|c|c|c|c|c|}
\hline & \multicolumn{14}{|c|}{ Quadrados Médios } \\
\hline & EC & DF & CF & $\mathrm{CP}$ & $M(g)$ & PH & AT & SST & RAZÃO & CS & DS & ES & MS(g) & NS \\
\hline Genótipo & $0,0028^{\text {ns }}$ & $0,0503^{\star *}$ & $0,2^{* *}$ & $0,152^{*}$ & $0,157^{\text {ns }}$ & $5,98^{\star *}$ & $0,58^{\star *}$ & $116,8^{\star *}$ & $579,23^{\star *}$ & $0,0084^{\text {ns }}$ & $0,012^{* *}$ & $0,0043^{* *}$ & $0,025^{\text {ns }}$ & $37,22^{* *}$ \\
\hline C.V (\%) & $40,40 \%$ & $7,02 \%$ & $8,94 \%$ & $14,34 \%$ & $34,43 \%$ & $4,49 \%$ & $19,22 \%$ & $19,57 \%$ & $40,16 \%$ & $16,22 \%$ & $16,03 \%$ & $24,67 \%$ & $42,84 \%$ & $16,07 \%$ \\
\hline
\end{tabular}

Significativo, em nível de $5 \%$ de probabilidade pelo teste F; NS - não significativo.

TABELA 2. Médias de cinco características de porte e nove de fruto em P. foetida L. UFPB, Areia, PB, 2010.

\begin{tabular}{|c|c|c|c|c|c|c|c|c|c|c|c|c|c|c|}
\hline & EC & DF & CF & $\mathrm{CP}$ & $M(g)$ & $\mathrm{pH}$ & AT & SST & RAZÃO & CS & DS & ES & MS(g) & NS \\
\hline Acesso & $0,089 a$ & $1,550 a b$ & $1,497 \mathrm{~b}$ & $1,701 \mathrm{~b}$ & $1,348 \mathrm{a}$ & $3,786 \mathrm{c}$ & $0,86 a$ & $12,5 \mathrm{a}$ & $14,66 \mathrm{~b}$ & $0,53 \mathrm{a}$ & $0,25 b$ & $0,11 \mathrm{~b}$ & $0,402 a$ & $16,06 a b$ \\
\hline Acesso 2 & $0,076 a$ & $1,516 b$ & $1,745 a$ & $1,819 a b$ & $1,131 \mathrm{a}$ & $3,606 \mathrm{c}$ & $0,42 c$ & $5,6 \mathrm{~d}$ & $14,72 \mathrm{~b}$ & $0,54 a$ & $0,27 a b$ & $0,14 a b$ & $0,402 a$ & $15,06 b$ \\
\hline Acesso 3 & $0,114 a$ & $1,481 b$ & $1,724 a$ & $1,843 a b$ & $1,129 a$ & $4,598 \mathrm{~b}$ & $0,786 a$ & $8,53 \mathrm{c}$ & $10,83 b$ & $0,58 \mathrm{a}$ & $0,31 \mathrm{a}$ & $0,14 a b$ & $0,398 a$ & $18,73 a$ \\
\hline Acesso 4 & $0,098 a$ & $1,635 a$ & $1,8 \mathrm{a}$ & $1,843 a b$ & $1,32 a$ & $4,712 b$ & $0,46 \mathrm{bc}$ & $10,1 \mathrm{bc}$ & $25,86 \mathrm{a}$ & $0,54 \mathrm{a}$ & $0,25 b$ & $0,14 \mathrm{a}$ & $0,418 a$ & $18,13 a$ \\
\hline Acesso 5 & $0,091 \mathrm{a}$ & $1,568 \mathrm{ab}$ & $1,688 a$ & $1,972 \mathrm{a}$ & $1,221 \mathrm{a}$ & $5,08 \mathrm{a}$ & $0,542 b$ & $11,93 a b$ & $22,45 a$ & $0,52 \mathrm{a}$ & $0,24 \mathrm{~b}$ & $0,15 \mathrm{a}$ & $0,496 \mathrm{a}$ & $18,13 a$ \\
\hline
\end{tabular}

As médias seguidas de uma mesma letra não diferem estatisticamente pelo teste de Tukey a $5 \%$ de probabilidade. (Means followed by the same letter do not differ by Tukey test at $5 \%$ probability). ${ }^{*} \mathrm{EC}=$ espessura da casca (cm); DF= diâmetro do fruto $(\mathrm{cm})$; $\mathrm{CF}=$ comprimento do fruto $(\mathrm{cm}) ; \mathrm{CP}=$ comprimento do pedicelo $(\mathrm{cm}) ; \mathrm{M}=\mathrm{massa}$ do fruto $(\mathrm{g})$; $\mathrm{pH}=$ potencial hidrogenionico; $\mathrm{AT}=$ acidez titulável $(\mathrm{ml})$; SST = teor de sólidos solúveis ( $\left.{ }^{\circ} \mathrm{Brix}\right)$; RAZÃO= relação entre SST/AT; CS = comprimento da semente $(\mathrm{cm}) ; \mathrm{DS}=$ diâmetro da semente $(\mathrm{cm}) ; E S=$ espessura da semente $(\mathrm{cm}) ; \mathrm{MS}=\mathrm{massa}$ da semente $(\mathrm{g})$; NS= número de semente (un).

=3.7). Em relação ao Teor de sólidos Solúveis (TSS) e Acidez titulável (AT), as melhores performances foram dos genótipos 1 e 3, respectivamente. Essa variabilidade físico-química da espécie $P$. foetida $L$. já havia sido relatada por Jesús Aular et al. (2003), os quais observaram que a característica TSS foi a que apresentou maior variabilidade entre os genótipos.

Em relação ao número de sementes conforme observado por Meletti et al. (1994), há uma relação direta entre a alta viabilidade polínica e o número de sementes por fruto, também constatado no presente experimento (tabela 2).

Os genótipos 1, 4 e 5 apresentaram as maiores médias em relação ao diâmetro e comprimento do fruto, $\mathrm{pH}, \mathrm{AT}$ eTSS, respectivamente. Uma vez que na formação de um banco de germoplasma desejam-se frutos maiores, em função de maior quantidade de sementes. Frutos grandes também são de grande interesse para a farmacopéia, pois quanto maior o fruto, maior a quantidade de polpa, concentração de ácidos orgânicos, carotenóides, aminoácidos, vitaminas, flavonóides e, por conseguinte, mais matéria prima para elaboração de xaropes, emplastros entre outros produtos.

\section{CONCLUSÃO}

A diversidade genética encontrada nos acessos estudados para características de qualidade dos frutos e sementes de $P$. foetida $L$ é de interesse no melhoramento da espécie. Dentre os genótipos, os acessos 1, 4 e 5 apresentaram as maiores médias para as características diâmetro e comprimento do fruto, $\mathrm{pH}$, acidez titulável e teor de sólidos solúveis, e podem ser interessantes para cruzamentos visando a obtenção de uma população base para melhoramento da espécie.

\section{REFERÊNCIA}

AOAC: Official methods of analysis. Association of official Analytical Chemistry. Washington DC. 13th edition, 1980.

ARAÚJO, F.P.; SILVA, N.; QUEIROZ, M.A. Divergência genética entre acessos de passiflora cincinnata mast com base em descritores morfoagronômicos. Revista Brasileira de Fruticultura. Jaboticabal - SP, v. 30 , n. 3 , p.723-730, 2008.

AULAR, J.; RODRIGUEZ, Y. Algunas características físicas y químicas del fruto de cuatro espécies de passiflora. Revista Brasileira de Fruticultura, 15. 2003. BERNACCI, L.C.; MELETTI, L.M.M.; SOARES-SCOTT M.D.; PASSOS I.R.S.; JUNQUEIRA N.T.V. Espécies de maracujá: caracterização e conservação da biodiversidade. In: FALEIRO FG; JUNQUEIRA NTV; BRAGA MF (Eds). Maracujá: germoplasma e melhoramento genético. Planaltina-DF: Embrapa Cerrados. 2005. p.559-586.

CAMARGO, M.T.L.A. Etnofarmacobotânica: conceituação e metodologia de pesquisa. Humanitas/ FFLCH/USP: Terceira margem, São Paulo, 2003.

CERVI, A. C. Passifloraceae do Brasil. estudo do gênero Passiflora L., subgênero Passiflora. Madrid: Fontqueira XLV, 1997. 92p.

CHOPRA, R.N.; BADHWAR, R.L.; GHOSH, S. Poisonous Plants of India. Public 127 Service Commission, Govt. of West Bengal, Calcutta, India, 1944. 469p. 
CHOPRA, R.N.; NAYAR, S.L.; CHOPRA, I.C. Glossary of Indian Medicinal Plants. CSIR, New Delhi, India, p.18687,1956 .

CRUZ, C.D. Programa Genes: Aplicativo computacional em genética e estatística. UFV, Viçosa, Brasil, 2001. 648pp.

DHAWAN, K; DHAWAN S; SHARMA, A. Passiflora: a review update. J.Ethnopharmacol. v.94, 2004. p.1-23.

DI STASI, L.C. Plantas medicinais: arte e ciência. Um guia de estudo interdisciplinar/ Luiz Cláudio Di Stasi organizador. Editora da Universidade Estadual Paulista, São Paulo, 1996.

DHAWAN, K; KUMAR, S; SHARMA, A. Anxiolytic activity of aerial and underground parts of Passiflora incarnata. Fitoterapia, 72, p.922-926, 2001.

JUNQUEIRA, N.T.V; SANTOS E.C; JUNQUEIRA K.P; FALEIRO F.G; ELLON G; BRAGA M.F. Características físico-químicas e produtividade de acessos de passiflora nitida kunth procedentes do centro-norte do brasil. Revista Brasileira de Fruticultura. v.32, 2010. p.791-797. KILLIP, E. P. The American species of Passifloraceae. Field Museum of Natural History,

Botanical Séries, Chicago, v. 19, p. 1-613, 1938.

HOEHNE, F.C. Frutas indígenas. São Paulo: Instituto de Botânica, 1946. 88p.

LOPES, S.C. Citogenética do maracujá, Passiflora spp. In: SÃO JOSÉ, AR. A cultura do maracujá no Brasil. Jaboticabal: FUNEP, 1991. p.201-209.

MARTINELLI, L.A.; SILVA, A.M.; CAMARGO, P.B; MORETTI, L.R; TOMAZELLI, A.C; SILVA, D.M.L; FISCHER, E.G; SONODA, K.C \& SALOMÃO, M.S.M.B. Levantamento das cargas orgânicas lançadas nos rios do estado de São Paulo. Biota Neotropica 2, 2002.1-18p.

MACIEL, M.A.M. et al. Plantas medicinais: a necessidade de estudos multidisciplinares. Quim Nova 25: p. 429438, 2002.

Medical Dictionary Definitions. Definition of Biliousness. Disponível em:<http://www.medterms.com/script/main/ art.asp?articlekey=19438>. Acesso em: 10 de abr. 2011. MELETTI, L.M.M; BERNACCI, L.C; SOARES-SCOTT, M.D;
AZEVEDO FILHO, J.A; MARTINS, A.L.M. Variabilidade genética em caracteres morfológicos, agronômicose citogenéticos de populações de maracujazeiro-doce (Passiflora alata Curtis.). Revista Brasileira de Fruticultura, Jaboticabal, v. 25, n. 2, p. 275-278, 2003. MELETTI, L.M.M; SOARES-SCOTT, M.D; BERNACCI, L.C.; PASSOS, I.R.S. Melhoramento genético do maracujá: passado e futuro. In: FALEIRO FG; JUNQUEIRA NTV; BRAGA MF (Eds). Maracujá: germoplasma e melhoramento genético. Planaltina- DF: Embrapa Cerrados. 2005. p.55-78.

NWOSU, M.O. Herbs for mental disorders. Fitoterapia 70, p.58-63, 1999.

PREGNOLLATTO, W; PREGNOLLATTO, N.P. Normas analíticas do Instituto Adolfo Lutz. São Paulo: Instituto Adolfo Lutz, 1985. 26p.

RATES, S.M.K. Plants as source of drugs. Toxicon: official journal of the International Society on Toxinology 39: p. 603-613, 2001.

REGO, M.M.; BRUCKNER, C.H.; SILVA, E.A.M.; FINGER, F.L.; SIQUEIRA, D.L.; FERNANDES, A.A. Self incompatibility in passion fruit: evidence of two locus genetic control. Theoretical and Applied Genetics, New York, v. 98, 1999. p. 564-568.

SWARBRICK, J. T. Weeds of Australia, Salviniaceae, Primulaceae, Pontederiaceae. Aust. Weeds, v. I, n. I0, 1981. 21-27p.

SOUZA, M.M.; PEREIRA, T.N.S.; SILVA, L.C.; REIS, D.S.S.; SUDRÉ, C.P. Karyotype of six Passiflora species collected in the state of Rio de Janeiro. Cytologia: 2003. p165-171.

ULMER, T; MACDOUGAL J.M. Passiflora: Passionflowers of the world. Portland: Timber Press, 2004. 27p.

VANDERPLANK, J. Passion flowers. Cambridge: The MIT Press, 2000. 224p.

WAGNER, W.L; HERBST, D.R; SOHMER, S.H.. Manual of the flowering plants of 153 Hawai'i. 2 vols. Univ. of Hawaii Press \& Bishop Museum Press, Honolulu. 1990. p.853.

Rev. Bras. PI. Med., Botucatu, v.13, especial, p.569-573, 2011. 